\title{
Dielectric properties of proton conductor $\mathrm{BaCe}_{0.9} \mathrm{Y}_{0.1} \mathrm{O}_{3-\delta}$
}

\author{
Hiroshi YAMAMURA, Yorinobu KATOH, Takenori YOKOTE and Katsuyoshi KAKINUMA
}

Department of Material and Life Chemistry, Faculty of Engineering, Kanagawa University, 3-27-1, Rokkakubashi, Kanagawa-ku, Yokohama 221-8686

\begin{abstract}
Frequency dependences of the dielectric constant $\left(\varepsilon_{\mathrm{r}}{ }^{\prime}\right)$ were investigated for the perovskite-type oxide $\mathrm{BaCe}_{0.9} \mathbf{Y}_{0.1} \mathbf{O}_{3-\delta}$, which is a typical proton conductor. Numerical calculation of the frequency dependence of $\varepsilon_{\mathrm{r}}^{\prime}$ clarified that the large $\varepsilon_{\mathrm{r}}{ }^{\prime}$ originated from the superimposition of both electrolyte-electrode interfacial and Debye-type polarizations. The Debye-type polarizations which originated from the dopant-vacancy associates, $\left(\mathrm{Y}_{\mathrm{Ce}^{\prime}}{ }^{\prime}-\mathrm{V}_{\ddot{o}}\right)^{\bullet}$ were depressed under wet Ar atmosphere. Therefore, it can be speculated that the proton may occur according to the following equilibrium equation: $\mathrm{H}_{2} \mathrm{O}+\mathrm{V}_{\mathrm{o}} \Leftrightarrow 2 \mathrm{H}^{\bullet}+\mathbf{O}_{\mathrm{o}}{ }^{\times}$.
\end{abstract}

Key-words: Proton conduction, Dielectric constant, Debye-type polarization, Oxygen vacancy, Defect associate

[Received November 14, 2007; Accepted J anuary 17, 2008] @2008 The Ceramic Society of Japan

1. Introduction

The proton conductor can be applied to many devices such as hydrogen sensors, hydrogen fuel cells and hydrogen separation membranes. It is well known that $\mathrm{BaCeO}_{3}$-based perovskite-type oxides show proton conduction at elevated temperatures under $\mathrm{H}_{2}$ or $\mathrm{H}_{2} \mathrm{O}$ atmosphere, when $\mathrm{Ce}^{4+}$ was partially substituted by trivalent cation. ${ }^{1)-8)}$ It has been discussed that the proton conduction would occur according to the following equilibrium equations:

$$
\left.\mathrm{H}_{2} \mathrm{O}+\mathrm{V}_{\mathrm{O}}^{\ddot{2}} \Longleftrightarrow 2 \mathrm{H}^{\bullet}+\mathrm{O}_{\mathrm{O}} \times 7\right)
$$

or

$$
\mathrm{H}_{2} \mathrm{O}+\mathrm{V}_{\ddot{\mathrm{O}}}+\mathrm{O}_{\mathrm{O}} \times 2 \mathrm{OH}_{\mathrm{O}}{ }^{\cdot 8)}
$$

However, it has not been clear so far which mechanism is dominant factor for the proton conduction.

Recently, the present authors ${ }^{9)-10)}$ have clarified using the computer simulation technique that the frequency dependence of $\varepsilon_{\mathrm{r}}{ }^{\prime}$ and $\varepsilon_{\mathrm{r}}{ }^{\prime \prime}$ in the $\mathrm{Sm}$-doped $\mathrm{CeO}_{2}$ system, which is typical oxide-ion conductor, could be explained by the superimposition of electrolyte-electrode interfacial polarization and Debye-type polarization due to dopant-vacancy associate.

In the present study, the frequency dependence of $\varepsilon_{\mathrm{r}}{ }^{\prime}$ for $\mathrm{BaCe}_{0.9} \mathrm{Y}_{0.1} \mathrm{O}_{3-\delta}$ which is a typical proton conductor were investigated in order to clarify the proton-conduction mechanism in atmosphere containing $\mathrm{H}_{2} \mathrm{O}$ vapor.

\section{Experimental procedure}

Powder samples of the perovskite-type oxide $\mathrm{BaCe}_{0.9}$ $\mathrm{Y}_{0.1} \mathrm{O}_{3-\delta}$ were synthesized by a solid-state reaction, using $\mathrm{CeO}_{2}$ (99.99\%, High Purity Chemicals), $\mathrm{BaCO}_{3}$ (99.9\%, Wako Pure Chemical Industries) and $\mathrm{Y}_{2} \mathrm{O}_{3}(99.9 \%$, High Purity Chemicals) as starting materials.

Weighed powders were wet ball-milled for $24 \mathrm{~h}$ using a milling pot made of synthetic resin and resin-coated balls, and ethanol as a dispersion reagent. The dried powder mixtures were calcined at $1273 \mathrm{~K}$ for $10 \mathrm{~h}$ in air. After sieving with a mesh size of $53 \mu \mathrm{m}$ in, the powder samples were uniaxially molded at a pressure of $5 \mathrm{MPa}$ and then subjected to rubber pressing at $200 \mathrm{MPa}$. The compacts thus obtained were sintered at $1673 \mathrm{~K}$ for $10 \mathrm{~h}$ in air. The relative densities of the sintered specimens, which were estimated from their geometrical dimensions and weight, were $86.4 \%$. On the other hand, a fluorite-type oxide $\mathrm{Ce}_{0.7} \mathrm{Yb}_{0.3} \mathrm{O}_{2-\delta}$ was also prepared with the similar process by using $\mathrm{CeO}_{2}$ and $\mathrm{Yb}_{2} \mathrm{O}_{3}$ (99.9\%, Furuuchi Chemicals) as starting materials in order to compare with $\mathrm{BaCe}_{0.9} \mathrm{Y}_{0.1} \mathrm{O}_{3-\delta}$.

The powdered samples were characterized by means of an X-ray diffraction (XRD) (model: Multi Flex, Rigaku Co.) with monochromated $\mathrm{CuK} \alpha$ radiation. Lattice constant was determined from XRD peaks by a least square method, using Si powder as an external standard.

Dielectric constant $\left(\varepsilon_{\mathrm{r}}^{\prime}\right)$ was measured as a function of frequency by the ac two-probe method in the temperature range from 573 to $1073 \mathrm{~K}$ under dry and wet Ar atmosphere. The wet Ar atmosphere was obtained by flowing Ar gas (70 $\mathrm{dm}^{3} / \mathrm{min}$ ) saturated with water vapor at $313 \mathrm{~K} . \mathrm{H}_{2} \mathrm{O}$ partial pressure of dry- and wet-Ar atmosphere are estimated to be 6.6 $\mathrm{Pa}$ and $2.6 \times 10^{3} \mathrm{~Pa}$, respectively. An impedance analyzer (4192A LF, Yokogawa-Hewlett-Packard) was used for the measurements of both $\varepsilon_{\mathrm{r}}{ }^{\prime}$ and ac conductivity $\left(\sigma_{\mathrm{ac}}\right)$ in the frequency range of $5 \mathrm{~Hz}$ to $13 \mathrm{MHz}$. The $\sigma_{\mathrm{ac}}$ was estimated from the intercept of real plane in the impedance spectra. The dimensions of the sintered disk for the ac conductivity measurements were $10 \mathrm{~mm}$ in diameter and $2 \mathrm{~mm}$ in thickness. For all the measurements, a platinum electrode was attached to both sides of the specimen by firing at $1223 \mathrm{~K}$ for 30 min in air. Kaleida Graph (Synergy Software) was used for the numerical calculation of the dielectric parameters.

\section{Results and discussion}

XRD experiments clarified that $\mathrm{BaCe}_{0.9} \mathrm{Y}_{0.1} \mathrm{O}_{3-\delta}$ was a single phase of perovskite-type structure having an orthorhombic symmetry with lattice parameters, $a=0.8744, b=0.6219$, $c=0.6238 \mathrm{~nm} \quad\left(V=0.3392 \mathrm{~nm}^{3}\right)$, which was very close to the values of non-doped $\mathrm{BaCeO}_{3}$, in spite of the Y-doping. ${ }^{7)}$

Figure 1 shows Arrhenius plots of $\sigma_{\mathrm{ac}}$ which was measured under both dry and wet Ar atmospheres. The $\sigma_{\mathrm{ac}}$ values under the wet Ar atmosphere were larger than those under the dry Ar one over the measuring temperature range. This experimental fact suggests that $\mathrm{BaCe}_{0.9} \mathrm{Y}_{0.1} \mathrm{O}_{3-\delta}$ is a proton conductor, as reported in various references. ${ }^{1)-8)}$ The activation energies for the electrical conduction under dry and wet 


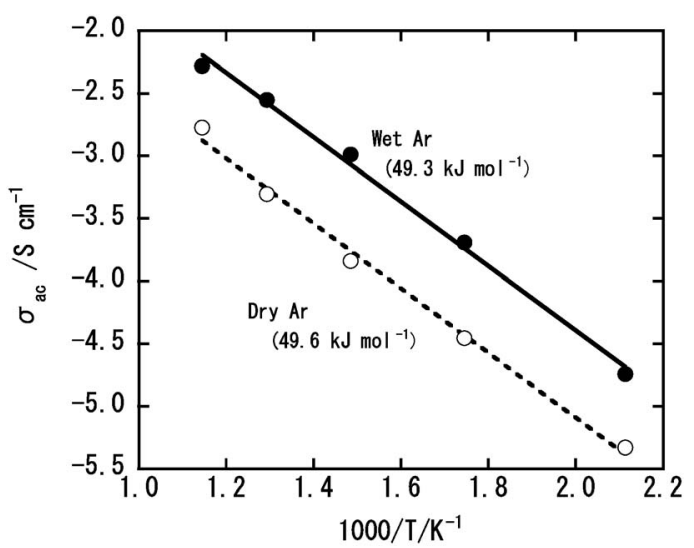

Fig. 1. Arrhenius plots of $\sigma_{\text {ac }}$ of $\mathrm{BaCe}_{0.9} \mathrm{Y}_{0.1} \mathrm{O}_{3-\delta}$ observed under the dry and wet Ar atmospheres. Numbers in parenthesis represents the activation energy.

Ar atmosphere were estimated to be 49.6 and $49.3 \mathrm{~kJ} \mathrm{~mol}^{-1}$, respectively.

In order to investigate the dynamic property of ions in the proton conductor under electric field, the computer simulation for the frequency dependence of dielectric constant $\left(\varepsilon_{\mathrm{r}}{ }^{\prime}\right)$ was tried, assuming that $\varepsilon_{\mathrm{r}}{ }^{\prime}$ will be given by the following equation according to our earlier studies: ${ }^{9)-10}$ )

$$
\varepsilon_{\mathrm{r}}^{\prime}=\varepsilon_{\mathrm{r} \infty}+\frac{\varepsilon_{\mathrm{r} 0}-\varepsilon_{\mathrm{r} \infty}}{1+\left(\omega \tau_{\mathrm{o}}\right)^{2}}+\frac{\varepsilon_{\mathrm{r}}(0)}{\omega^{s}},
$$

where $\omega$ is the angular frequency $(=2 \pi f), \tau_{\mathrm{o}}$ is the dipole relaxation time, $\varepsilon_{\mathrm{r} 0}$ and $\varepsilon_{\mathrm{r} \infty}$ are the low- and high-frequency limit of dielectric constant for the Debye-type polarization. $\varepsilon_{\mathrm{r}}(0)$, which varies inversely with frequency, represents the dielectric constant due to the electrode-electrolyte interfacial polarization at the low-frequency limit. The exponent of frequency $(s)$ is the parameter which was introduced in order to generalize the equation as a function of frequency. In Eq. (3), the first two terms of the right side represent the Debye-type dispersion, and the third term does the frequency dependence of $\varepsilon_{\mathrm{r}}(0)$. The theoretical approach for the dielectric property is given elsewhere. ${ }^{9)-12)}$

A typical example of curve fitting for $\varepsilon_{\mathrm{r}}{ }^{\prime}$ observed at $573 \mathrm{~K}$ under dry Ar atmosphere is shown in Fig. 2, where the solid line represents the values estimated through the computer simulation according to Eq. (3). The observed and calculated values agree with each other, where the correlation factor $(R)$ is $98.9 \%$. The dotted and broken lines in Fig. 2 represent the estimated components of dielectric constant $\left(\varepsilon_{\mathrm{r}}^{\prime}\right)$ due to the Debye type polarization and the interfacial polarization $\left(\varepsilon_{\mathrm{r}}(0)\right)$, respectively. Both the Debye-type polarization $\left(\varepsilon_{\mathrm{ro}}=9.3 \times 10^{2}\right)$ with the relaxation frequency of $8.5 \times 10^{5} \mathrm{~Hz}$ and the very large electrode-electrolyte polarization $\left(\varepsilon_{\mathrm{r}}(0)=2.6 \times 10^{8}\right)$ are observed in the frequency dependence of $\varepsilon_{\mathrm{r}}{ }^{\prime}$. The Debye-type polarization observed can be ascribed to the dipole moment of the dopant-vacancy associate such as $\left(\mathrm{Y}_{\mathrm{Ce}}{ }^{\prime}-\mathrm{V}_{\mathrm{O}}\right)^{\bullet}$ in the oxygen deficient perovskite-type structure, as discussed in the $\mathrm{Sm}$-doped $\mathrm{CeO}_{2}$ system having a fluorite-type structure. ${ }^{9)-10)}$

Figure 3 shows the frequency dependence of $\varepsilon_{\mathrm{r}}{ }^{\prime}$ for $\mathrm{BaCe}_{0.9} \mathrm{Y}_{0.1} \mathrm{O}_{3-\delta}$ at various temperatures, 373-673 $\mathrm{K}$, under the dry Ar atmosphere. Although no dielectric relaxation due to the Debye-type polarization is observed at $373 \mathrm{~K}$, it

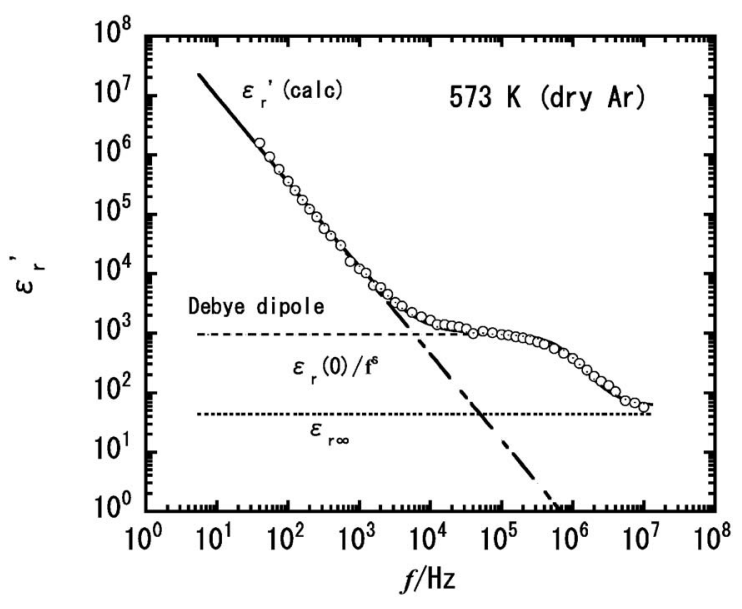

Fig. 2. Result of the numerous calculations for $\mathrm{BaCe}_{0.9} \mathrm{Y}_{0.1} \mathrm{O}_{3-\delta}$ at $573 \mathrm{~K}$ under dry $\mathrm{Ar}$ atmosphere; observed value $(\bigcirc)$, calculated value $(-)$, Debye dipole $(---), \varepsilon_{\mathrm{r}}^{\prime}(0) / f^{\mathrm{s}}(-\cdot-\cdot), \varepsilon_{\mathrm{r} \infty}(\cdots \cdots)$.

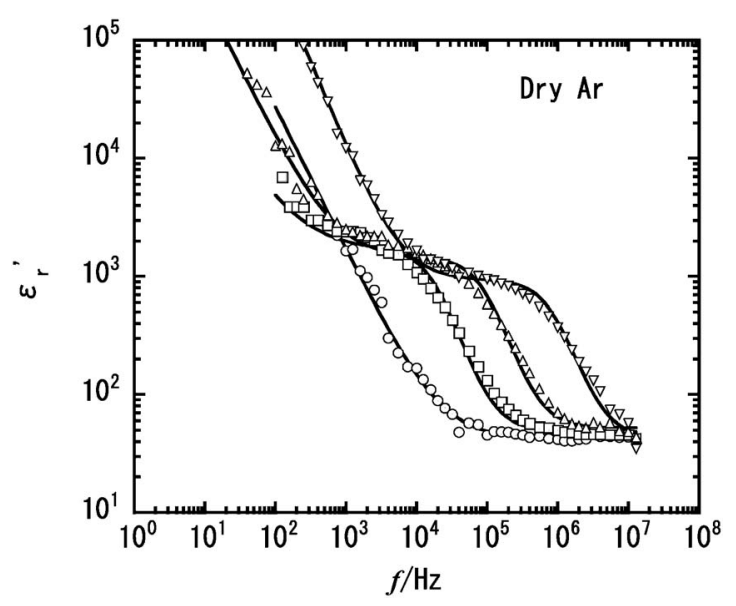

Fig. 3. Frequency dependences of $\varepsilon_{\mathrm{r}}{ }^{\prime}$ of $\mathrm{BaCe}_{0.9} \mathrm{Y}_{0.1} \mathrm{O}_{3-\delta}$ under dry Ar at various temperatures, $373(\bigcirc), 423(\square), 473(\triangle)$ and $573 \mathrm{~K}$ $(\nabla)$.

appears at $423 \mathrm{~K}$ and then shifts to the high-frequency region with increasing the temperatures. The dielectric parameters estimated in the present study are summarized in Table 1. The $\varepsilon_{\mathrm{r}}(0)$ values increase with increasing the measuring temperatures. On the other hand, $\varepsilon_{\text {ro }}$ shows the maximum value at $423 \mathrm{~K}$, and then decreases gradually. As the present sample contains oxygen vacancy corresponding to the doped $\mathrm{Y}^{3+}$ contents, the equilibrium reaction between the dopantvacancy associates and separate $\mathrm{Y}_{\mathrm{Ce}}^{\prime}$ and $\mathrm{V}_{\ddot{\mathrm{O}}}$ can be described as follows.

$$
\left(\mathrm{Y}_{\mathrm{Ce}}{ }^{\prime}-\mathrm{V}_{\ddot{\mathrm{O}}}\right)^{\prime}{ }_{\mathrm{m}} \Leftrightarrow \mathrm{Y}_{\mathrm{Ce}}{ }^{\prime}+\mathrm{V}_{\ddot{\mathrm{O}}},
$$

where $\left(\mathrm{Y}_{\mathrm{Ce}}{ }^{\prime}-\mathrm{V}_{\mathrm{O}}{ }^{\prime \bullet}{ }_{\mathrm{m}}{ }_{\mathrm{m}}\right.$ represents the associates responsible to electric field, which could contribute to the dielectric constant. When the measuring temperature increases, the equilibrium will shift to the right hand. Therefore, the dielectric constant will decrease, but the conductivity will increase. This discussion was supported by the experimental result that the $\varepsilon_{\text {ro }}$ values above $523 \mathrm{~K}$ decreased with increasing temperature. The s values, which should be unity for an ideal 
Table 1. Dielectric Parameters in $\mathrm{BaCe}_{0.9} \mathrm{Y}_{0.1} \mathrm{O}_{3-\delta}$ under Dry and Wet Ar Atmosphere

(a) dry Ar atmosphere

\begin{tabular}{|c|c|c|c|c|c|c|}
\hline Temp. $(\mathrm{K})$ & 423 & 473 & 523 & 573 & 623 & 673 \\
\hline$\varepsilon_{\mathrm{r}}(\mathrm{O})$ & $3.2 \times 10^{5}$ & $3.7 \times 10^{6}$ & $7.1 \times 10^{7}$ & $2.6 \times 10^{8}$ & $8.3 \times 10^{8}$ & $1.8 \times 10^{9}$ \\
\hline $\mathrm{s}$ & 1.0 & 1.2 & 1.4 & 1.4 & 1.5 & 1.5 \\
\hline$\varepsilon_{\mathrm{r}}$ & $1.7 \times 10^{3}$ & $1.4 \times 10^{3}$ & $1.3 \times 10^{3}$ & $9.3 \times 10^{2}$ & $5.6 \times 10^{2}$ & $4.1 \times 10^{2}$ \\
\hline$\varepsilon_{\infty}$ & 49 & 53 & 51 & 44 & 68 & 160 \\
\hline$\tau_{0}(\mathrm{~s})$ & $\mathbf{9 . 1 \times 1 0 ^ { - 6 }}$ & $\mathbf{1 . 8 \times 1 0 ^ { - 6 }}$ & $5.2 \times 10^{7}$ & $1.9 \times 10^{-7}$ & $1.3 \times 10^{-7}$ & $\mathbf{1 . 5 \times 1 0 ^ { - 7 }}$ \\
\hline$f_{\mathrm{o}}(\mathrm{Hz})$ & $1.8 \times 10^{4}$ & $9.1 \times 10^{4}$ & $3.1 \times 10^{5}$ & $8.4 \times 10^{5}$ & $1.3 \times 10^{6}$ & $1.0 \times 10^{6}$ \\
\hline
\end{tabular}

(b) wet Ar atmosphere

\begin{tabular}{|c|c|c|c|c|c|c|}
\hline Temp.(K) & 423 & $\mathbf{4 7 3}$ & 523 & 573 & $\mathbf{6 2 3}$ & $\mathbf{6 7 3}$ \\
\hline$\varepsilon_{\mathrm{r}}(0)$ & $3.8 \times 10^{5}$ & $4.9 \times 10^{7}$ & $3.0 \times 10^{8}$ & $1.2 \times 10^{9}$ & $2.4 \times 10^{9}$ & $4.6 \times 10^{9}$ \\
\hline $\mathrm{s}$ & 1.0 & $\mathbf{1 . 4}$ & $\mathbf{1 . 5}$ & 1.5 & $\mathbf{1 . 5}$ & $\mathbf{1 . 5}$ \\
\hline$\varepsilon_{\mathrm{ro}}$ & 870 & $6.0 \times 10^{2}$ & $4.2 \times 10^{2}$ & $3.3 \times 10^{2}$ & $2.7 \times 10^{2}$ & $1.0 \times 10^{3}$ \\
\hline$\varepsilon_{\infty}$ & 50 & 51 & 51 & 54 & 82 & 180 \\
\hline$\tau_{\mathrm{o}}(\mathrm{s})$ & $6.8 \times 10^{6}$ & $1.1 \times 10^{-6}$ & $2.8 \times 10^{7}$ & $\mathbf{1 . 2 \times 1 0 ^ { - 7 }}$ & $8.3 \times 10^{-8}$ & $2.9 \times 10^{-6}$ \\
\hline$f_{\mathrm{o}}(\mathrm{Hz})$ & $2.4 \times 10^{4}$ & $1.5 \times 10^{5}$ & $5.7 \times 10^{5}$ & $1.4 \times 10^{6}$ & $1.9 \times 10^{6}$ & $5.4 \times 10^{4}$ \\
\hline
\end{tabular}

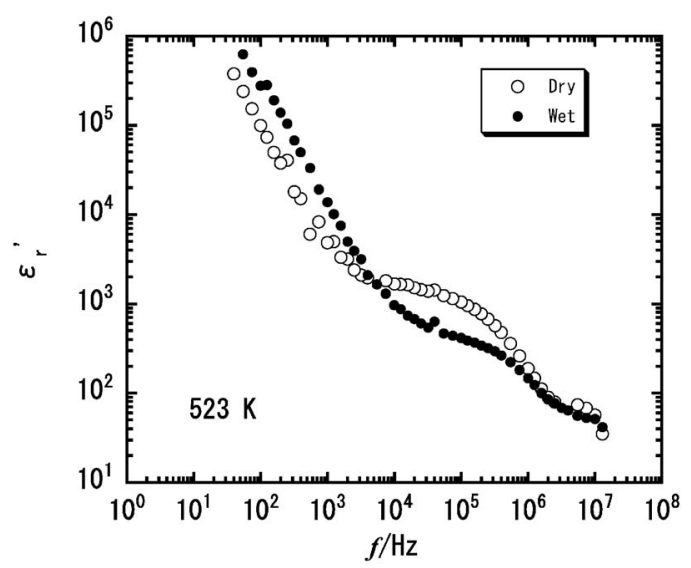

Fig. 4. Frequency dependences of $\varepsilon_{\mathrm{r}}{ }^{\prime}$ of $\mathrm{BaCe}_{0.9} \mathrm{Y}_{0.1} \mathrm{O}_{3-\delta}$ under the dry $(\bigcirc)$ and wet $(O)$ Ar atmospheres at $523 \mathrm{~K}$.

system, gradually increased from 1.0 to 1.5 with increasing the temperature. Although the physical meaning of $\mathrm{s}$ has not been clarified, it may have a close relation to the interaction between the mobile ion and the electrode.

Figure 4 typically shows the frequency dependence of $\varepsilon_{\mathrm{r}}{ }^{\prime}$ at $523 \mathrm{~K}$ under the dry and wet Ar atmosphere. It can be obviously seen that under the wet Ar atmosphere the Debyetype polarization $\left(\varepsilon_{\mathrm{r} 0}\right)$ remarkably depresses from 1300 to 420 , and oppositely the $\varepsilon_{\mathrm{r}}(0)$ value increases from $7.1 \times 10^{7}$ to $3.0 \times 10^{8}$, comparing with those measured under the dry Ar atmosphere (Table 1). The large depression of $\varepsilon_{\mathrm{r} 0}$ under the wet Ar atmosphere means the decrease in the Debye-type dipoles due to the uptake of water vapor into the crystal lattices. Therefore, the proton conduction may occur according to Eq. (1), because the $\left(\mathrm{Y}_{\mathrm{Ce}}{ }^{\prime}-\mathrm{OH}_{\mathrm{O}}{ }^{\circ}\right)$ type associate, which may occur according to Eq. (2), must show the Debye-type dipole moment under the wet Ar atmosphere. Furthermore, the increase in $\varepsilon_{\mathrm{r}}(0)$ under the wet $\mathrm{Ar}$ atmosphere may correspond to the increase in the protons which were moved from $\mathrm{H}_{2} \mathrm{O}$, resulting in the increase in the proton conduction.

Arrhenius plots of $\varepsilon_{\mathrm{r}}(0)$, which were estimated from the

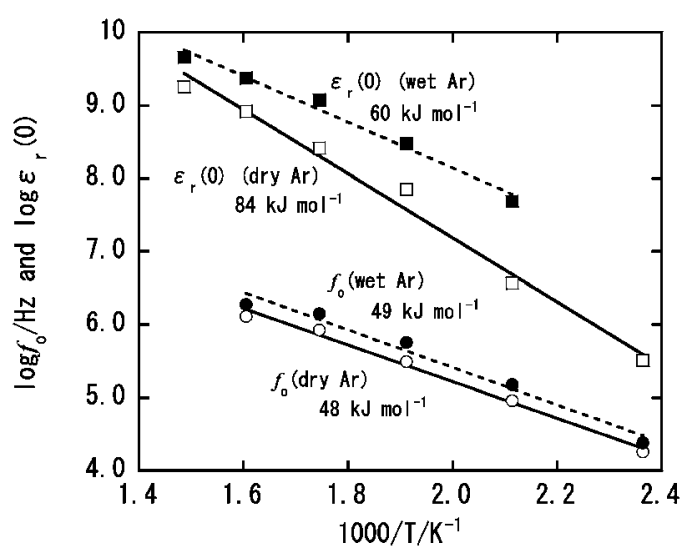

Fig. 5. Arrhenius plots of $\varepsilon_{\mathrm{r}}{ }^{\prime}(0)$ of $\mathrm{BaCe}_{0.9} \mathrm{Y}_{0.1} \mathrm{O}_{3-\delta}$ under dry $\mathrm{Ar}$ $(\square)$ and wet $\operatorname{Ar}(\square)$, and $\varepsilon_{\text {ro }}$ under dry $\operatorname{Ar}(\bigcirc)$ and wet $\operatorname{Ar}($

analysis of $\varepsilon_{\mathrm{r}}{ }^{\prime}$ under both dry and wet Ar atmospheres are shown in Fig. 5. The activation energies for $\varepsilon_{\mathrm{r}}(0)$ were estimated to be 84.0 and $60.2 \mathrm{~kJ} \mathrm{~mol}^{-1}$ in dry and wet $\mathrm{Ar}$ atmospheres, respectively. Ma et al. ${ }^{7)}$ have reported that the activation energy for the proton conduction of $\mathrm{BaCe}_{0.9}$ $\mathrm{Y}_{0.1} \mathrm{O}_{3-\delta}$ under wet air was estimated to be $\sim 60 \mathrm{~kJ} \mathrm{~mol}^{-1}$, which was lower than that under dry air. Therefore, the activation energy for the electrical conduction under the wet Ar atmosphere in the present study may correspond to the proton conduction. Bohn and Schober ${ }^{13)}$ have reported the high activation energy $\left(\sim 100 \mathrm{~kJ} \mathrm{~mol}^{-1}\right)$ for oxide-ion conduction of $\mathrm{BaZr}_{0.9} \mathrm{Y}_{0.1} \mathrm{O}_{2.95}$ under dry air. Therefore, the activation energy for the electrical conduction under the dry Ar atmosphere may correspond to the oxide-ion conduction.

On the other hand, Arrhenius plots of the relaxation frequency $\left(f_{\mathrm{o}}\right)$ of the Debye-type dipole, which was estimated from the analysis of $\varepsilon_{\mathrm{r}}^{\prime}$ in both dry and wet $\mathrm{Ar}$ atmospheres, are also shown in Fig. 5. The activation energies for the two types of $f_{\mathrm{o}}$ were estimated to be 48 and $49 \mathrm{~kJ}$ $\mathrm{mol}^{-1}$ in dry and wet Ar atmospheres, respectively, which agree with the values of $\sigma_{\mathrm{ac}}$, as shown in Fig. 1. These activation energies for $f_{\mathrm{o}}$ may correspond to the thermal exciting processes of the Debye-type associates. Concerning the low-activation energy for $f_{\mathrm{o}}$, Greenwood ${ }^{14)}$ has discussed that the activation energy for the diffusion of the associates is lower than that of the separate vacancies and therefore permit ready transfer of matter but such pairs cannot contribute to the electrical conductivity which requires independent migration of the vacancies in opposite directions.

In the present study, we propose that the proton conduction occurs due to the incorporation of $\mathrm{O}$ of $\mathrm{H}_{2} \mathrm{O}$ into the oxygen vacancies, resulting in both the depression of the Debye-type dipole moment and the increase in the interfacial polarization. In order to confirm this speculation, we tried to investigate the dry or wet atmospheric effect on the dielectric properties of the oxygen deficient fluorite-type oxide $\mathrm{Ce}_{0.7} \mathrm{Yb}_{03} \mathrm{O}_{2-\delta}$, which is an oxide-ion conductor. ${ }^{15)}$ Figure 6 shows the Arrhenius plots of $\sigma_{\mathrm{ac}}$ of $\mathrm{Ce}_{0.7} \mathrm{Yb}_{03} \mathrm{O}_{2-\delta}$ under the dry and wet atmosphere. There was no difference between their electrical conductions, for which the activation energies were estimated to be $98 \mathrm{~kJ} \mathrm{~mol}^{-1}$. This activation energy suggests that the oxide-ion conduction, not proton conduction, occurs. Figure 7 shows the frequency depen- 


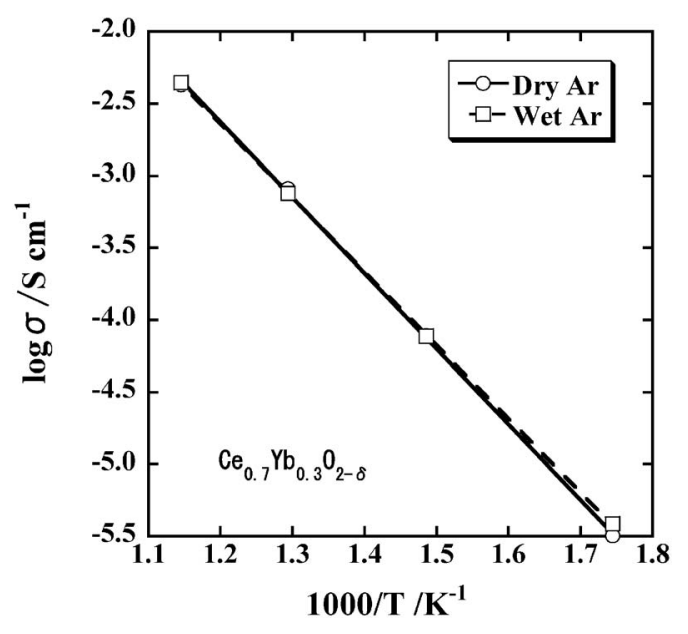

Fig. 6. Arrhenius plots of $\sigma_{\text {ac }}$ of $\mathrm{Ce}_{0.7} \mathrm{Yb}_{0.3} \mathrm{O}_{2-\delta}$ observed under the dry and wet Ar atmospheres.

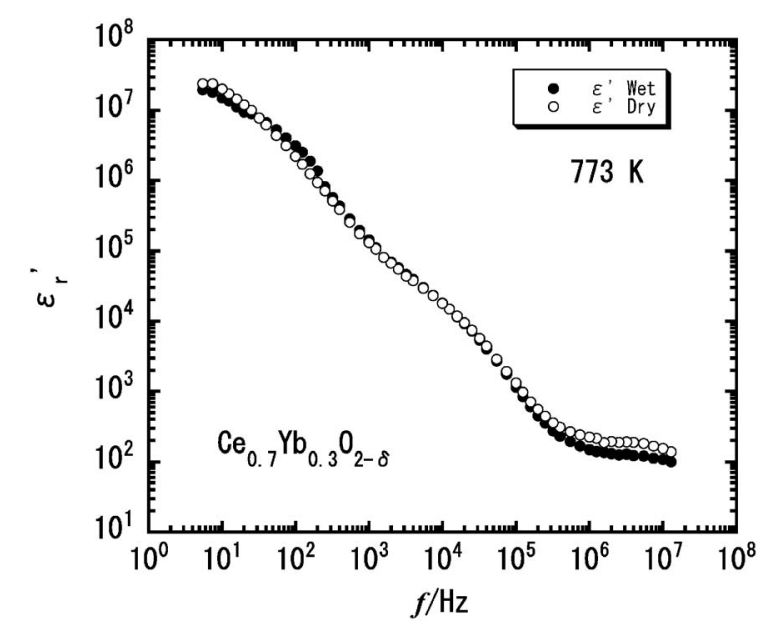

Fig. 7. Frequency dependences of $\varepsilon_{\mathrm{r}}{ }^{\prime}$ of $\mathrm{Ce}_{0.7} \mathrm{Yb}_{0.3} \mathrm{O}_{2-\delta}$ under the dry $(\bigcirc)$ and wet $(-)$ Ar atmospheres at $773 \mathrm{~K}$.

dence of $\varepsilon_{\mathrm{r}}{ }^{\prime}$ at $773 \mathrm{~K}$ for $\mathrm{Ce}_{0.7} \mathrm{Yb}_{03} \mathrm{O}_{2-\delta}$ in the dry and wet atmosphere. We could not observe such a difference in the $\varepsilon_{\mathrm{r}}{ }^{\prime}$ that was observed for the $\mathrm{BaCe}_{0.9} \mathrm{Y}_{0.1} \mathrm{O}_{3-\delta}$. This fact may strongly support that the depression in the Debye-type dipole moment and the increase in the interfacial polarization due to the incorporation of $\mathrm{H}_{2} \mathrm{O}$ in the lattice has a close relation with the proton conduction. On the other hand, there still remains a question why the oxygen vacancies in $\mathrm{BaCe}_{0.9}$ $\mathrm{Y}_{0.1} \mathrm{O}_{3-\delta}$ having the perovskite-type structure can uptake oxygen or water vapor and those in $\mathrm{Ce}_{0.7} \mathrm{Yb}_{0.3} \mathrm{O}_{2-\delta}$ having a fluorite-type structure cannot do.

\section{Conclusion}

Dielectric properties were investigated for $\mathrm{BaCe}_{0.9} \mathrm{Y}_{0.1} \mathrm{O}_{3-\delta}$ having an orthorhombic perovskite-type structure, which is a typical proton conductor. Numerical analyses of the frequency dependence of $\varepsilon_{\mathrm{r}}{ }^{\prime}$ clarified that the large $\varepsilon_{\mathrm{r}}{ }^{\prime}$ originated from the superimposition of both electrolyte-electrode interfacial and Debye-type polarizations. The Debye-type polarizations, which were ascribed to defect associates $\left(\mathrm{Y}_{\mathrm{Ce}}{ }^{\prime}-\mathrm{V}_{\mathrm{O}}\right)^{\cdot}$ on the basis of the activation energy, remarkably decreased under the wet $\mathrm{Ar}$ atmosphere. Therefore, the occurrence of the protons may obey the following equilibrium equations, $\mathrm{H}_{2} \mathrm{O}+\mathrm{V}_{\ddot{\mathrm{O}}}^{\bullet} \Leftrightarrow 2 \mathrm{H}^{\bullet}+\mathrm{O}_{\mathrm{O}}{ }^{\times}$. This speculation was supported by the dielectric behavior of $\mathrm{Ce}_{0.7} \mathrm{Yb}_{0.3} \mathrm{O}_{2-\delta}$ which shows no proton conduction. On the other hand, the activation energies for $\varepsilon_{\mathrm{r}}(0)$ under dry and wet Ar corresponded to those of oxide-ion and proton conductivities, respectively.

Acknowledgements This study was supported by the Scientific Frontier Research Project of the Ministry of Education, Culture, Sports, Science and Technology, Japan.

\section{References}

1) H. Iwahara, H. Uchida, K. Ono and K. Ogaki, J. Electrochem. Soc., 135, 529-533 (1988).

2) F. Chen, P. Wang, O. T. Sorensen, G. Meng and D. Peng, $J$. Matr. Chem., 7, 1533-1539 (1997).

3) K. D. Kreuer, E. Schonherr and J. Maier, Solid State Ionics, 70/71, 278-284 (1994).

4) T. Yajima and H. Iwahara, Solid State Ionics, 47, 117-124 (1991).

5) K. Katahira, Y. Kohichi, T. Shimura and H. Iwahara, Solid State Ionics, 138, 91-98 (2000).

6) T. Schober, Solid State Ionics, 145, 319-324 (2001).

7) G. Ma, T. Shimura and H. Iwahara, Solid State Ionics, 110, 103-110 (1998).

8) K. Takeuchi, C.-K. Loong, J. W. Richardson Jr., J. Guan, S. E. Dorris and U. Balachandran, Solid State Ionics, 138, 63-77 (2000).

9) H. Yamamura, S. Takeda, H. Nishino, K. Kakinuma and Y. Takeda, J. Ceram. Soc. Japan, 115, 23-27 (2007).

10) H. Yamamura, S. Takeda, H. Nishino and K. Kakinuma, $J$. Ceram. Soc. Japan, 115, 264-268 (2007).

11) H. Yamamura, S. Takeda, H. Nishino and K. Kakinuma, Electrochem., 75, 719-724 (2007).

12) H. Yamamura, S. Takeda, H. Nishino and K. Kakinuma, Solid State Ionics, 178, 889-893 (2007).

13) H. G. Bohn and T. Schober, J. Am. Ceram. Soc., 83, 768-772 (2000).

14) N. N. Greenwood, "Ionic Crystals-Lattice Defects and Nonstoichiometry", Butterworth, London (1968) pp. 79.

15) H. Yamamura, J. Satake, M. Saito and K. Kakinuma, Jpn. J Appl. Phys. (in press). 